www.jmscr.igmpublication.org

Impact Factor (SJIF): 6.379

Index Copernicus Value: 79.54

ISSN (e)-2347-176x ISSN (p) 2455-0450

crossrefDOI: https://dx.doi.org/10.18535/jmscr/v6i12.89

\title{
Study to assess the pattern of coronary artery disease (CAD) in Sagar town of Bundelkhand region, Madhya Pradesh
}

Authors

\section{Dr Prayank Jain MD; DM, Dr Achla Jain MBBS}

Corresponding Author

Dr Prayank Jain MD; DM

\section{Background}

Globally, coronary artery disease (CAD) has assumed epidemic proportions. In 2015, CAD affected 110 million people and caused in 8.9 million deaths ${ }^{(1)(2)}$ which is $15.6 \%$ of all deaths, making it the most common cause of death globally. ${ }^{(2)}$ Once considered a disease of developed nations, $\mathrm{CAD}$ is now increasingly found in developing countries like India. According to Registrar General of India, CAD caused $23 \%$ of all deaths and $32 \%$ of all adult deaths in 2010-2013

Understanding the pattern of coronary artery disease $(\mathrm{CAD})$ in a particular region is essential to plan development of necessary infrastructure to prevent and treat the patients of CAD. Not many studies describing pattern of coronary artery disease (CAD) among patients of bundelkhand region is available till now. To address this issue we studied the pattern of CAD among all coronary angiographies (CAG) done in our hospital (bhagyodaya tirth hospital) in Sagar, a major town of Bundelkhand, Madhya Pradesh.

\section{Objective}

To study the pattern of coronary artery disease in Sagar town of Bundelkhand region, Madhya Pradesh.

\section{Materials and Methods}

A total of 158 coronary angiogrphies (CAG) from $7 / 2 / 18$ to $7 / 12 / 18$ were studied retrospectively. Lesion severity of $>50 \%$ in main vessels (LMCA, LAD, LCX, RCA, RAMUS) was used as the criteria for significant CAD.

\section{Results}

Single vessel disease was found in 45 patients, Double vessel disease was found in 37 patients, Triple (or more) vessel disease was found in 45 patients. Slow flow without obstructive CAD was found in 6 patients and normal coronaries were found in 25 patients. Left Main Coronary Artery (LMCA) was found in 3 patients, Left Anterior Descending (LAD) disease was found in 101 patients, Left Circumflex (LCX) Disease was found in 67 patients, Right Coronary Artery (RCA) disease was found in 84 patients. Ramus intermedius (RAMUS) disease was found in 8 patients. LMCA/3VD was present in $48(30.37 \%)$ patients who are much more than what was found in most of the western world studies. 
Table 1

\begin{tabular}{|l|c|}
\hline Coronary Artery Affected & Number of Patients \\
\hline LMCA & 3 \\
\hline LAD & 101 \\
\hline LCX & 67 \\
\hline RCA & 84 \\
\hline RAMUS & 8 \\
\hline
\end{tabular}

Table 2

\begin{tabular}{|l|c|}
\hline $\begin{array}{l}\text { Number of Coronary Arteries } \\
\text { Affected }\end{array}$ & $\begin{array}{c}\text { Number of } \\
\text { Patients }\end{array}$ \\
\hline Single Vessel Disease (SVD) & 45 \\
\hline Double Vessel Disease (DVD) & 37 \\
\hline Triple Vesel Disease (TVD) & 45 \\
\hline Non Obstructive Cad With Slow Flow & 6 \\
\hline Lmca or Tvd & 48 \\
\hline Normal Coronaries & 25 \\
\hline
\end{tabular}

\section{Conclusion}

Extensive CAD (LMCA/TVD) was found in much more proportion of patients than reported in previous studies. These findings suggest the need for planning and development of state of art treatment facilities to treat such patients.

\section{References}

1. GBD 2015 Disease and Injury Incidence and Prevalence, Collaborators. (8 October 2016). "Global, regional, and national incidence, prevalence, and years lived with disability for 310 diseases and injuries, 1990-2015: a systematic analysis for the Global Burden of Disease Study 2015". Lancet. 388 (10053): 1602. doi:10.1016/S0140-6736(16)316786. PMC 5055577. PMID 27733282

2. GBD 2015 Mortality and Causes of Death, Collaborators. (8 October 2016). "Global, regional, and national life expectancy, allcause mortality, and cause-specific mortality for 249 causes of death, 1980 2015: a systematic analysis for the Global Burden of Disease Study 2015". Lancet. 388 (10053): 14591544. doi:10.1016/S0140-6736(16)310121. PMC 5388903. PMID 27733281 